\title{
Prognostic value of intraductal carcinoma for adjuvant radiotherapy candidates after radical prostatectomy
}

\author{
Sedat Karakoc ${ }^{1}$, Serdar Çelik ${ }^{1}$, Nilhan Akbulut ${ }^{1}$, Ozan Bozkurt ${ }^{1}$, Hulya Ellidokuz ${ }^{1}$, Burçin \\ Tuna $^{1}$, Kutsal Yörükoğlu ${ }^{1}$, and Mehmet Uğur Mungan ${ }^{1}$ \\ ${ }^{1}$ Dokuz Eylül University
}

December 11, 2020

\begin{abstract}
ABSTRACT Objective: We aimed to investigate the prognostic significance of intraductal carcinoma in radical prostatectomy (RP) specimens and predictive value of IDC-P for biochemical recurrence and adjuvant therapy decision. Method: Patients who underwent RP between 2000-2014 with final pathological stage pT3a and negative surgical margins (Group 1, n=35) and pT2 with positive surgical margins (Group 2, $\mathrm{n}=32$ ) were included. RP specimens were re-evaluated for the presence of IDC-P component and other prognostic factors. In both groups, prognostic factors were compared according to the presence of IDC-P and biochemical recurrence status. Results: In group 1, IDC-P was detected in 5 cases and biochemical recurrence was detected in 3 cases. Patients with IDC-P showed significantly higher biochemical recurrence than those without IDC-P ( $\mathrm{p}=0.002)$. In univariate analysis, IDC-P was found to be significantly associated with worse progression free survival ( $\mathrm{p}<0.001)$. In group 2 , IDC-P was detected in 4 cases and biochemical recurrence was detected in 10 cases. Also, tumor volume was significantly higher in patients with IDC-P than those without IDC-P $(\mathrm{p}=0.02)$. IDC-P was also significantly associated with worse progression free survival in group $2(\mathrm{p}=0.033)$. Conclusions: In both groups, IDC-P is a prognostic factor for progression free survival and / or biochemical recurrence. Especially in these patients, presence of IDC-P might be helpful for postoperative adjuvant therapy management decision. Keywords: radical prostatectomy, intraductal carcinoma of prostate (IDC-P), prostate cancer, biochemical recurrence, progression free survival.
\end{abstract}

\section{Hosted file}

Manuscript.pdf available at https://authorea.com/users/357657/articles/498239-prognosticvalue-of-intraductal-carcinoma-for-adjuvant-radiotherapy-candidates-after-radicalprostatectomy

\section{Hosted file}

Tables.pdf available at https://authorea.com/users/357657/articles/498239-prognosticvalue-of-intraductal-carcinoma-for-adjuvant-radiotherapy-candidates-after-radicalprostatectomy

\section{Hosted file}

Figures.pdf available at https://authorea.com/users/357657/articles/498239-prognosticvalue-of-intraductal-carcinoma-for-adjuvant-radiotherapy-candidates-after-radicalprostatectomy 